\title{
CLANDESTINIDAD Y LUCHA ARMADA: UNA MIRADA DESDE EL GÉNERO. EL CASO DE "MERY" EN LA CLANDESTINIDAD DEL PARTIDO COMUNISTA DE CHILE
}

\author{
Javiera Libertad Robles Recabarren ${ }^{1}$
}

\section{Resumen:}

El presente trabajo centra su preocupación en la participación de la mujer en la lucha contra la dictadura militar de Chile (1973 - 1988), con el objetivo de ir develando las relaciones de género establecidas dentro de la militancia clandestina. Para su realización, se acude a la memoria suelta de una mujer militante del Frente Patriótico Manuel Rodríguez, quien a través del testimonio de sus vivencias expone aspectos de la vida militante desde su posición de mujer, madre y clandestina, que permiten develar el lugar que ocupaban las mujeres en el brazo armado del Partido Comunista de Chile.

Palabras-claves: Género. Militancia. Identidad.

\section{Memoria e identidad: aspectos teóricos}

Mery ${ }^{2}$ es actualmente una señora de 68 años de edad que vive en una de las comunas periféricas de Santiago. Su aspecto físico no presenta las huellas ingratas que dejan el paso del tiempo. Por el contrario, se mantiene activa participando en organizaciones vecinales, en política mediante sus reuniones con antiguos compañeros de militancia y cuidando su hermano y sobrino enfermos. Actualmente Mery tiene tres nietas del único hijo que tuvo y no mantiene una relación de pareja, tónica que se ha repetido a lo largo de los años, dice que "ya se le pasó el tren" y es muy tarde para encontrar un compañero de vida.

El aspecto de una señora dulce, tierna y preocupada de sus familiares más cercanos no hace pensar el pasado que vivió. Este se encuentra marcado por la militancia política, pues desde muy joven ingresó al Partido Comunista de Chile (PCCh) a través del trabajo de masas enfocado a los y las niñas menores de 15

\footnotetext{
${ }^{1}$ Professora de História e Ciências Sociais e Graduada em Educação pela Universidade Academia de Humanismo Cristiano, Providencia, Santiago, Chile Mestranda em História e Memória da Universidade Nacional de La Plata, La Plata, Argentina. E-mail: libertad.recabarren@gmail.com

${ }^{2}$ Mery es el nombre de combate que usaba la entrevistada en el periodo de clandestinidad. Pidió expresamente que se mantuviera en reserva su verdadero nombre para efectos del presente trabajo.
} 
años, Pioneros. Posteriormente pasa a formar parte de las Juventudes Comunistas, estructura política donde se le promovió a los equipos de autodefensa de masas y de política militar del PCCh y es ahí donde el Golpe Militar de 1973, que acaba con el gobierno de Salvador Allende, la encuentra militando.

Luego de un periodo de inestabilidad política y social producto del terrorismo de Estado de los primeros años de dictadura, se logra organizar una estructura político militar para la resistencia y el combate contra el dominio imperante. El Frente Patriótico Manuel Rodríguez (FPMR) sale a la luz en 1983 y constituye el brazo armado del PCCh. Mery fue parte de su formación y trayectoria, militando activamente en la orgánica del FPMR hasta su disolución

Ahora bien, al enfocar nuestro trabajo al contexto histórico de la dictadura militar de Chile y a la organización de la resistencia a la represión desde el testimonio de una combatiente, se hace necesario comprender los aspectos teóricos que influyen en la construcción y relato de la memoria suelta (STERN, 2002) de Mery. Los elementos fundamentales que la constituyen y sus eventuales tensiones con aspectos relacionados a las relaciones de género dentro de la orgánica partidaria.

Es así que su vida militante constituye una parte importante en la construcción de su relato identitario, proceso que se caracteriza por estar mediado por múltiples factores, conflictos y contradicciones, en un constante re acomodo entre cómo nos vemos a sí mismos y qué espera la sociedad de nosotros/as. Pues tal como nos plantea Jorge Larraín (2001) el concepto de identidad no corresponde a una esencia innata o a una conceptualización proveniente desde la mismidad individual, sino más bien corresponde a un proceso de construcción social, por medio del cual los/as individuos/as se van definiendo a través de interrelaciones simbólicas con el resto.

En este sentido, la memoria constituye un elemento fundamental en la construcción de los discursos identitarios de los sujetos, se encuentran indisociables debido a que es por medio de la memoria, de un relato común del pasado, que un grupo social forja su identidad. En el caso de Mery, ella construye su relato identitario mediante la selección selectiva de su pasado militante, resultando muy complejo en las entrevistas realizadas separar aspectos de su vida que se encuentren "vaciados de contenido político". Para Bruno Groppo la relación entre memoria e identidad es intrínseca y parte de un proceso conjunto. Es así que para la construcción de un relato identitario de un grupo social o de un sujeto, la memoria 
constituye el punto de partida, la base material para su configuración. Para el historiador, la identidad es "el producto de un proceso histórico que se apoya sobre la memoria y que, como la memoria, funciona dentro de ciertos marcos sociales", (2002, p. 190), donde "el trabajo ininterrumpido de la memoria modifica continuamente la identidad" (GROPPO, 2002, p. 190).

Sobre la base de las consideraciones anteriores, la identidad de los individuos se instala en un entrecruce de una diversidad de memorias $y$, por tanto, de identidades. Pues al encontrarse la construcción del relato identitario siempre en constante diálogo con un otro, los sujetos conviven con una diversidad de grupos. No obstante, en el caso que nos atañe, la memoria/identidad de Mery, al vivir episodios traumáticos y fuera de la normalidad social, como es la vivencia de la clandestinidad, el pasado reciente y su participación como militante contra la dictadura, pareciera ser esa memoria la dominante en su discurso identitario. En consecuencia, es el sentido de pertenencia a un grupo el que otorga a su vez un sentido de identidad a los sujetos, de ahí que el conjunto de identidades personales se encuentran enraizadas en contextos colectivos culturalmente.

En relación a lo anterior, el factor de la militancia política, en un contexto de alta politización de la vida cotidiana, aparece ante nuestros ojos como elemental en cuanto intentamos estudiar la construcción del relato identitario de una mujer militante. Es la configuración que hacemos del yo, conjunto a los patrones simbólicos establecidos y el sentido de pertenencia hacia un grupo en particular, el que nos interesa en su interrelación entre la construcción de las identidades personales y las identidades colectivas. De ahí que el concepto de identidad siempre suponga un proceso de constante interacción entre subjetividades diversas, es siempre un proceso intersubjetivo de reconocimiento mutuo, pues supone la existencia de otros con modos de vida, valores, costumbres e ideas diferentes.

Los patrones simbólicos y los roles establecidos por la sociedad para hombres y mujeres, también son componentes centrales en la construcción de los discursos identitarios de los sujetos. Es así que los elementos culturales y aprendidos socialmente configuran lo femenino y lo masculino, estereotipos que constituyen nuestra identidad de género. En este sentido, es muy probable que haya sido diferente ser una mujer militante que un hombre militante dentro de las filas del Partido Comunista de Chile y del Frente Patriótico Manuel Rodríguez, pues son los roles y estereotipos que se encuentran asociados al ser mujer y al ser hombre los 
que median, eventualmente, las relaciones de género y de poder dentro de las filas partidarias.

De acuerdo a dicha categorización, mujeres y hombres son dotados de determinadas expectativas y evaluaciones por parte del contexto social que se inscriben, donde se establecen los roles sociales, actitudes y disposiciones que ha de desarrollar cada cual de acuerdo a su condición de género, develando la representación intersubjetiva y el conjunto de características compartidas por un colectivo (COLÁS, 2006). En este proceso, las experiencias enraizadas en la tradición poseen también gran relevancia en la constitución identitaria, puesto que éstas promueven representaciones y prácticas compartidas en relación a lo que es ser mujer y hombre, ser sujeto masculino o femenino. Mediadas a su vez por un conjunto de representaciones reproducidas históricamente.

Ahora bien, cabe preguntarnos qué tipo de relación existe entre nuestro interés por ir develando los hilos de nuestro pasado reciente y la construcción identitaria de los sujetos que lo vivieron. ¿Es acaso relevante buscar comprender las tensiones existentes en el relato identitario de una mujer militante, en relación a los elementos partidarios, sociales y culturales de una época? ¿Por qué el afán de estudiar la vida cotidiana, identidad de género y política, y su eventual relación con la lucha armada en un contexto de terrorismo de Estado?

Dichas interrogantes surgieron al momento de sistematizar el interés por el relato de Mery. Por qué rescatar su testimonio de aquella memoria cada vez más frágil por el pasar de los años. Cómo es posible justificar académicamente el hecho de querer visibilizar el papel de la mujer en la lucha clandestina a partir de un solo relato, porqué el de ella y no el de otras. Es en este ejercicio de argumentación de la presente investigación que se ha considerado pertinente acudir a los aportes que Cristina Moyano ha realizado a la historia política y al estudio de la historia del tiempo presente. Ella nos plantea la necesidad de considerar la subjetividad como un elemento trascendental al querer estudiar el partido como una comunidad de sujetos que está en cada uno de ellos, porque más que discurso ideológico, fue constructor de una identidad colectiva, donde el individuo explica y entiende su vida partidaria y política. En este sentido, son las variables subjetivas, de apropiación de significados, producción de sentidos y construcción de mapas mentales los que van re construyendo el proyecto partidario. 
En consecuencia, estudiar el testimonio de vida de una militante nos ayudaría a comprender en trabajos futuros, cómo los y las militantes viabilizaron un proyecto político a partir de sus propias vivencias y apropiaciones subjetivas que hicieron de él. Es la construcción que hacen de sí mismos en base a los patrones simbólicos y culturales de la estructura partidaria, los que van configurando su discurso (MOYANO, 2009, p. 50).

A lo largo de los planteamientos realizados, es posible evidenciar la importancia que existe en la construcción de identidad y nuestra memoria. Elementos que, como se planteó anteriormente, son indisociables producto de su constante interacción al momento de definirnos como sujetos. No obstante, los roles y estereotipos de género establecidos por el conjunto de la sociedad y que su internalización forja nuestra identidad de género, en base a lo que exige la sociedad de mi persona en cuanto hombre o mujer, sujeto femenino o masculino, también forman un aspecto central a la hora de comprender la participación de las mujeres dentro de la estructura partidaria. Cuál es el modelo de militante que se debe seguir, qué tipo de elementos priman para ser reconocida/o como un buen cuadro, interrogantes que se trabajarán a continuación y que buscarán develar cómo era ser una mujer militante.

\section{Ser mujer/ser militante: trayectorias de un relato de vida}

Es en el testimonio de Mery, en la historia de su vida, donde se mezclan fechas y situaciones complejas, sentimientos contradictorios y una visión retrospectiva de sus vivencias en la militancia armada, donde se buscará develar las tensiones existentes en la construcción del relato identitario. Relato que pone en evidencia los conflictos y problemáticas de género, donde ser mujer militante, soltera y madre en un contexto de lucha armada y clandestina nos dan pistas para develar cómo los sujetos van produciendo sentidos a partir de su compromiso político.

Mery comienza su testimonio, sin pregunta e interpelación previa, sólo esperando a ser escuchada por alguien que se mostrara interesada, más que en sus hazañas o anécdotas, en cómo ella enfrentó esa serie de elementos que ninguno de sus compañeros tuvo que hacer frente, como es el caso de la maternidad. Es así que, como un grito en el vacío, comienza su testimonio diciendo: "a mí me trataban 
igual que a un hombre,...no tenían diferencia en los tratos... yo perdí parte de mi feminidad en la lucha" (MERY, 2012).

Desde ahí la pérdida se presenta como una constante en todo su relato testimonial. La pérdida de la feminidad o de la condición de ser mujer siempre asociada a la maternidad, a la posibilidad de ser madre de más de un hijo y a formar una familia numerosa. Es desde la rabia y la pena por la pérdida de múltiples posibilidades a lo largo de su vida que van irrumpiendo entre las memorias de acciones militares y de su relato biográfico- político.

Para contextualizar desde dónde nos habla Mery y porqué finalmente mira desde el presente su historia militante con un dejo de amargura, es preciso reconstruir cómo ella llega a militar dentro de las filas partidarias y qué tipo de atribución le asigna el haber sido parte del PCCh en los 60's.

Fue a partir de una toma de terreno, lo que se conocería como la Población La Victoria, donde Mery tiene su primer acercamiento a las estructuras políticas del PCCh. De origen humilde y de familia proveniente de las salitreras, a los 11 años de edad integra las filas del Partido a través del trabajo de pioneros -trabajo político y de masas del PCCh orientado a los niños y niñas-, donde realizaba tareas comunitarias. El tránsito político para Mery se evidencia en su testimonio como algo natural, dado, sin mayores cuestionamientos y quiebres. Es finalmente la estructura partidaria el centro de su sociabilidad, su vida política aparece de esta forma como su vida, no existiendo separación aparente entre una y otra. Por el contrario, es posible poner de manifiesto que la construcción de su relato identitario se realiza a partir de los patrones sociales partidarios, grupo político-cultural que crea un sentimiento de pertenencia en el individuo militante, quien a su vez otorga sentido a su identidad a partir de la adscripción al PCCh.

En los 60' le designaron como trabajo de masas hacerse cargo del "Club de Muchachas Comunistas", organización que tenía por fines acercar a la comunidad el Partido a través de la reunión de las mujeres de la población, creando un espacio donde sociabilizar las tareas propias de su sexo, sin cuestionamiento alguno de su posición de subordinación. En este periodo, Mery integra las Juventudes Comunistas de Chile (JJCC) donde se le designan tareas consideradas apropiadas a su género, como es la reunión con las pobladoras o trabajo con los y las pioneras. Fue en ese contexto donde conoció a la mayoría de las que serían las futuras esposas y parejas 
de sus compañeros de armas, sin saber que su destino no sería pertenecer en el hogar y esperar la llegada de su compañero.

No es hasta los 16 años, a mediados de los 60', donde el Comité Central de las JJCC la requiere para formar equipos especializados en la autodefensa de masas y en la protección de la dirigencia partidaria. Es a partir de este acontecimiento que su vida tomó un nuevo giro, ahora pertenecería a grupos especiales con labores específicas, fuera de la cotidianidad del barrio y la estructura de base. Comienza a recibir instrucción de auto defensa personal y política, en otras palabras se inicia un trabajo político de cuadros con ella, donde la dimensión político - militar es central. Es preciso destacar, que en el testimonio de su vida militante, Mery nunca presentó quiebres en su narrativa que dieran aviso de un tránsito traumático entre los distintos episodios, de ahí que pareciera como algo natural, un caminar sin mayores baches ni cuestionamientos sobre su participación activa en el trabajo militar, para ella era parte de su deber ser de militante. Es decir, al primar en su construcción identitaria los elementos políticos y partidarios, nunca se cuestionó o al menos eso plantea en su testimonio-, seguir militando o cumpliendo las acciones que le designaban. Por el contrario, ella recibe las órdenes desde los equipos y estructuras correspondientes y ejecuta, era su deber ser.

Mery, la Negra como también la llamaban sus compañeros, lo que conocía como espacio de sociabilidad en su juventud fue la estructura partidaria. Ya en la segunda mitad de los 60' "era 100\% militante, lo único que he conocido es el partido, ha sido la política del Partido Comunista" (MERY, 2012), nos relata al preguntarle sobre su vida en este contexto. Poniendo en evidencia dos cosas, primero da cuenta de la existencia de un momento en que no se encontraba totalmente volcada a la tarea política, que en relación a la "línea de tiempo" que nos relata, corresponde a su trabajo previo a las JJCC, es decir, cuando integraba pioneros. Y segundo, nos devela la importancia atribuida a ser parte de la estructura partidaria, sentirse parte de un proyecto y posicionarse desde ahí para pensarse. Para ella toda su vida cotidiana estaba relacionada con el partido, sus reuniones, relaciones sociales, entre otros. Al vincularlo con el contexto en que se piensa este relato, segunda mitad de los 60', resulta muy dificultoso disociar la política de la vida cotidiana de los sujetos, la sociabilidad se encontraba inmersa, impregnada de apropiación política.

Tal como nos evidencia el relato de Mery, aparece muy dificultoso encontrar fracturas o distinciones entre su vida política y su cotidianidad previo golpe de 
Estado. De ahí que todas las preguntas o interpelaciones por parte de la investigadora a quien relatara sobre su infancia o experiencia, no necesariamente partidarias, se encuentran indisociablemente impregnadas de lo político.

Ahora bien, resulta oportuno precisar que los conflictos en cuanto a su relato identitario y las relaciones de género presentes en la estructura partidaria, se vinculan con los roles y estereotipos de género que la sociedad instala. A saber, son las exigencias sociales de género atribuidas al deber ser femenino -lo que espera la sociedad que sea yo por ser mujer ${ }^{3}$-, que se proyectan a su vez en la estructura partidaria donde las mujeres militantes ocupaban generalmente- y según el testimonio de la entrevistada-, un lugar de segundo orden ${ }^{4}$, los que no son seguidos por Mery. Pues ella no cumplía necesariamente con los patrones establecidos, por el contrario, mantenía una posición que se rebelaba ante ellos, como es su posición política dentro del PCCh, posteriormente la decisión de mantenerse sin pareja y criando a su hijo sola. Elementos todos que quiebran los patrones simbólicos establecidos en el conjunto de la sociedad.

No obstante, al momento en que Mery rememora y aboca a sus recuerdos, comienzan a surgir tensiones a lo largo de su testimonio. Tensión que se asocia a cómo ella evalúa hoy las decisiones que tomó en el contexto estudiado, evidenciando la presión del deber moral, de género que ejerce en la militante y que surge por medio de la palabra y el sentimiento de pérdida, la pérdida de su condición de ser mujer producto de las decisiones que ella tomó como militante." [...] yo perdí tener más hijos. Perdí mi condición de mujer y bueno fue algo como que yo estaba en mi salsa, ahora yo me doy cuenta todo lo que perdí, perdí demasiado"

¿Cómo se puede dejar de ser mujer? ¿Qué elementos se encuentran asociados a este sentimiento de pérdida? O más bien, cuáles son los elementos que hacen que una sea o no mujer para el sistema sexo género ¿qué se espera de ser mujer? Ser mujer, desde una perspectiva de género, se vincula con los patrones culturales que configuran "lo femenino", el que se encuentra asociado a un sistema binario con lo masculino. En este sentido, como opuestos complementarios, lo femenino se encuentra caracterizado por proyectar en el campo de lo social el rol de

\footnotetext{
${ }^{3}$ Dedicación al hogar, el cuidado de los otros, casarse y tener hijos; ser cariñosa y dulce; ser pasiva y sumisa en carácter, entre otras características asociadas a lo femenino.

${ }^{4}$ Posición caracterizada por ocupar cargos menores dentro de la estructura partidaria, orientados a la administración y el servicio. Situación que se acompaña con que a las militantes se les conocía como "la compañera de", no de forma autónoma.
} 
la maternidad, es decir, el cuidado de los otros, ser pasiva, emotiva y tierna entre otros aspectos.

En consecuencia, es posible que la pérdida se vincule con no cumplir las exigencias sociales que nos imponen como sujetos sexuados. No seguir con el patrón establecido en este sistema binario, produciría un quiebre en mi configuración de identidad, al no cumplir con lo establecido y ser juzgada implícitamente por el conjunto de la sociedad.

La imagen de las combatientes mujeres para la dictadura militar quebrantaba el estereotipo de mujer profundamente conservador instalado por los militares. La mujer según los agentes represivos debía seguir el rol del ideario mariano, recluida al hogar y al cuidado domésticos, de su familia e hijos. Por tanto, las mujeres combatientes rompen con los patrones establecidos, lo que las llevó a ser consideradas más peligrosas y doblemente reprimidas.

Elemento que también se presenta en la dictadura de Brasil, tal como nos plantea Andrei Martin San Pablo Kotchergenko al evidenciar que los actores que realizaron el golpe militar sostuvieron que el lugar de las mujeres se encontraba limitado a los cuidados domésticos o las obras de caridad. Asimismo, los agentes de la represión veían ?? a las mujeres militantes un enemigo más subversivo que a los combatientes hombres.

A ditadura militar chilena, assim como a brasileira, impôs uma ideologia que priorizava os moldes familiares tradicionais, marcados por um machismo exacerbado, e atribuía aos homens um papel autoritário, ressaltando o conservadorismo e o patriarcado. ${ }^{5}$

En un libro del Frente Patriótico Manuel Rodríguez emitido en el año 1986 contemporáneo a la resistencia armada- se alude en una entrevista con una combatiente, a la imagen que tenía la dictadura de las mujeres militantes. Al igual que en el caso de Brasil, se evidencia que la dictadura y los agentes de inteligencia veían en las mujeres un doble enemigo, un enemigo político y un enemigo ético moral. En el texto se relata una nota periodística de la época donde se menciona la participación de las mujeres en la lucha contra la dictadura y cómo eran enfrentados por los agentes.

\footnotetext{
5 "La dictadura militar chilena, así como la brasilera, impuso una ideología que priorizaba los moldes familiares tradicionales, marcados por un machismo exacerbado, y atribuía a los hombres un papel autoritario, resaltando el conservadurismo y el patriarcado" (KOTCHERGENKO, 2011, p. 284).
} 
Cuando el agente enfrenta a los terroristas, debe disparar primero sobre las mujeres, en caso de que lo hubiera', publicó una revista derechista [...] en noviembre de 1986 en Santiago. El artículo [...] trata de fundamentar que las mujeres son más peligrosas que los hombres, por lo que se debe aniquilar a ellas primero (FRENTE PATRIÓTICO MANUEL RODRÍGUEZ, 1986, p. $44-45)$.

El relato expuesto evidencia la doble represión ejercida hacia las mujeres, política y de género, como también el peso moral que recaía en las combatientes en ese contexto histórico. Cabe mencionar al respecto, que para Mery la decisión política de mantenerse sin pareja y criando sola a su hijo, viene a quebrantar el patrón de género de la dictadura, provocando en la actualidad una evaluación de sus decisiones.

Ahora bien, para el caso que nos atañe la condición de mujer y la posibilidad de tener hijos se presenta como una relación constante a lo largo del relato. De ahí que cuando Mery nos habla de esta pérdida de su feminidad, de ser mujer y de posibilidades, siempre están relacionadas con ser madre, y lo negativo que significó para ella tener sólo uno y no constituir una familia numerosa. En este sentido, el ser o no mujer no se encuentra asociado al encontrarse en pareja, vivir en matrimonio y/o tener la familia "ideal", sino más bien es la maternidad como elemento autónomo lo que hace que Mery se sienta desarraigada en su propio cuerpo actualmente.

Para Mery ser parte de una estructura política como fueron los equipos de autodefensa del PCCh previo a la dictadura, como posteriormente el FPMR, donde era una de las pocas mujeres militantes, esto nunca significó un impedimento aparente. Sin embargo, es posible evidenciar que para la militancia, que entrara una mujer a círculos masculinizados no representaba un conflicto en tanto la compañera era asumida como uno más, pero no en el reconocimiento de su feminidad y su diferencia, sino más bien obligándola implícitamente a seguir patrones simbólicos masculinos (BASABE; SADI, 2008). "Pienso yo que todos estos compañeros que entraron, entraron con la intención de verme como hombre a mí, no como mujer. Nunca se fijaron en mí como mujer y yo nunca tuve tiempo de enamorarme de nadie" (MERY, 2012).

Dicha situación que, tomando en consideración los olvidos propios de la memoria, da cuenta de cómo es finalmente ese tipo de experiencia, el ser negada en cuanto ser mujer por los otros, el grupo social al que pertenezco, tensiona 
profundamente la construcción identitaria. Pues si bien ella realizaba acciones en las mismas condiciones que sus compañeros, y era reconocida en cuanto a su rigurosidad y buen desempeño en ese tipo de tareas, al no ser reconocida como una mujer, es decir, en el marco de relaciones de pareja, produce fracturas al presentar elementos de tensión entre lo que ella considera como propio de ser mujer y lo que los otros piensan de ella.

\section{EI FPMR: género y militancia armada}

El Frente Patriótico Manuel Rodríguez surge en 1983 luego de un largo proceso de re articulación de la militancia y de la posición política del PCCh ante la dictadura mediante la creación del Programa de Rebelión Popular de Masa (PRPM). La construcción de las nuevas directrices políticas para derrotar a la dictadura comenzó a partir de las discusiones realizadas en Berlín, de la mano del diagnóstico realizado por antiguos militantes miembros de los escasos organismos de inteligencia que existían en la Unidad Popular.

El programa no sólo realiza un giro en la tradición pacífica y constitucionalista de la estructura partidaria del PCCh a una donde todos los medios de lucha eran considerados como válidos para derrotar la dictadura, sino que también logra realizar una síntesis en esa tradición sustentada en la movilización masiva de las masas con nuevos elementos de carácter político - militar. En este sentido, el PRPM encontró un método revolucionario a partir de las experiencias vividas en el Medio Oriente y Portugal, donde son las masas quienes logran derrotar a la dictadura, que en base al diagnóstico realizado por los encargados de crear una nueva política de acción era inviable combatir de forma directa al ejército militar sin el apoyo masivo de la totalidad de la población.

En consecuencia, la puesta en práctica en la década de los 80 de la PRPM década donde se conjugaron las condiciones propicias para un vuelco insurreccional, como fueron la institucionalización de la dictadura y la crisis del modelo capitalista-, tuvo como principal exponente la creación de un brazo armado del PC, conformada en el FPMR teniendo como objetivo el derrumbe de la dictadura en 1986. Considerado como el año decisivo donde el pueblo en su totalidad tomará el poder con ayuda de las fuerzas políticas - militares del partido. 
Es así que el objetivo que tenía el Frente Patriótico Manuel Rodríguez no era la formación de unas fuerzas armadas revolucionarias para la toma del poder, sino más bien ser un respaldo del pueblo para que éste se alzara contra la represión. Así lo deja de manifiesto José Miguel, comandante número uno del FPMR al plantear que

[...] cuando hablamos de sublevación popular, no estamos diciendo que haya que derrotar militarmente a las Fuerzas Armadas, sino de producir su desmoronamiento, e incluso su quiebre. Ello depende de la presión ejercida, por los niveles de enfrentamiento y de presencia de las organizaciones sociales, políticas y del pueblo en general (FRENTE PATRIÓTICO MANUEL RODRÍGUEZ, 1986, p. 79).

Resulta oportuno indagar en la imagen que tenía el FPMR hacia sus combatientes mujeres, como también el ideario de cuadro político ideal de la organización. En relación a esto último, se encuentra vinculado con características asociadas a la valentía, entereza, entrega, disciplina y fortaleza física y mental, aspectos que desde una perspectiva de género se vinculan con lo masculino. De esta forma, las mujeres que entraron a la organización debían adaptarse al ideario militante establecido y cumplir con lo exigido para ser consideradas como un par. Así lo pone de manifiesto el testimonio de Ana, combatiente del FPMR quien fue entrevistada en el libro emitido por la organización en 1986.

Cuando me incorporé a un grupo yo era la única mujer. Entonces tenía responsabilidades menores. Hacía cosas mínimas, se tomaba en cuenta mi condición de mujer. Pero yo me esforcé mucho. Quería que no hubiera diferencia y me preparaba igual que mis hermanos hombres (...). Luego con el tiempo me fui adaptando bastante bien y me fui ganando la confianza y el respeto de todos (FRENTE PATRIÓTICO MANUEL RODRÍGUEZ, 1986, p. 49).

El testimonio expuesto da cuenta del reconocimiento de las mujeres como militantes activas de la organización. No obstante también pone de manifiesto el trabajo que debían hacer las combatientes para ser valorizadas de igual forma y de esta manera ser asignadas acciones de mayor envergadura. Esta situación también se repite en el caso brasilero, donde las guerrilleras debían asimilarse al modelo de guerrillero establecido, de carácter masculinizante.

[...] algumas mulheres, para não ser discriminadas e sim aceitas e bem vistas como militantes, [...] assumiram a militância nas organizações de 
esquerda negando a sua condição de mulher. As organizações eram espaços fundamentalmente masculinos, o que impunha às mulheres a necessidade de se colocarem como militantes, diluindo as relações de gênero na luta política mais geral ${ }^{6}$ (KOTCHERGENKO, 2011, p. 292).

Ahora bien, volviendo al relato de Mery, ella integra las filas de la resistencia armada en la segunda mitad de los años 70 donde comienza prístinamente a re articularse una oposición a través de grupos como "Los Chicos Malos", el "Equipo Especial" o "Comando Manuel Rodríguez" (ROJAS. 2011, p. 213), los que posteriormente decantarían en el Frente Patriótico Manuel Rodríguez. Mery vivenció una serie de acontecimientos que la hicieron reafirmar su opción de mantenerse soltera y no desear emparejarse con ningún compañero, pues para ella significaría "dejar menos tiempo para las armas, era tiempo para el amor o dejar la lucha", (MERY, 2012), esa era su opción política que en este contexto cruza lo personal y lo cotidiano.

Al momento que Mery es consultada por si recuerda algún episodio o situación que la haya marcado como militante, nos relata una experiencia vivida por una compañera frentista, la única con la que participó en acciones que realizó y que recuerda. Fue en una de las primeras acciones, donde botar torres de electricidad en zonas cercanas a Santiago era la tarea principal. En aquella ocasión el grupo encargado de la acción tuvo un imprevisto al ser seguidos por carabineros, pasando toda la noche y parte de la madrugada, escondidos en la rivera de un río, resguardándose de la fuerza policial para no ser detenidos. La compañera luego de la larga noche pasada, al llegar a su casa fue golpeada por su pareja -quien también era del Frente Patriótico Manuel Rodríguez-, quien propinó en golpes debido a que no llegó a la hora correspondiente. La noticia se divulgó dentro de la organización, terminando ambos marginados por propia voluntad de la militancia.

Esta situación marcó a Mery, reafirmando su decisión de mantenerse sin pareja alguna, para ella esas compañeras sufrieron más porque eran doblemente reprimidas, por la dictadura y por sus maridos, independiente de si estos militaran o no. De ahí que la Negra nos plantea en su testimonio.

\footnotetext{
6 "Algunas mujeres para no ser discriminadas y ser aceptadas y bien vistas como militantes asumían la militancia en las organizaciones de izquierda negando su condición de mujer. Las organizaciones eran espacio fundamentalmente masculinos, y que empuja a las mujeres a la necesidad de ser reconocidas como militantes, diluyendo las relaciones de género en la lucha política más general".
} 
yo como era sola no tenía que darle explicaciones a nadie, nadie sabía lo que yo hacía tampoco. En esa parte yo era feliz, por la forma de vivir en que yo no tengo que darle explicaciones a nadie, por eso mismo fue mi opción de no estar en pareja (MERY, 2012).

En consecuencia, es posible plantear que Mery en la construcción de su relato identitario se configura en tensión, con fracturas y quiebres, los que hacen ruido cuando en un proceso retrospectivo mira su pasado y lo verbaliza. Enunciando sus memorias nos entrega pistas de cómo un sujeto militante siendo mujer e involucrada desde un principio en la resistencia armada en un partido conservador en materia de relaciones igualitarias de género, va dotando de sentido a las políticas del partido. Ella otorga sentido a su accionar en la lucha armada, y mira desde hoy al partido y sus compañeros desde otra óptica, desde aquellas fracturas que dejaron el largo trayecto recorrido entre el deber ser militante /ser mujer en la construcción de su relato identitario, donde son sus compañeros hombres los más afortunados según su testimonio, pues ellos no tuvieron que tranzar la vida familiar que ella si tuvo que poner a disposición de la lucha política.

De ahí que el relato de Mery nos provee de nuevos antecedentes en la visibilización de las mujeres en los grupos armados, ella tranzó la posibilidad de tener una familia más grande, seguir estudiando o ejercer su profesión por abocarse a la lucha contra la dictadura, todo menos su hijo quien aparece ante los ojos del presente como redención ante el pesar de sus acciones. Es en el frágil tiempo presente, en el ejercicio de re memorar y tejer los hilos de su historia, donde evalúa todo lo que tranzó y devela las relaciones de poder y de género existentes dentro de la estructura partidaria, donde las compañeras de estaban destinadas a quedarse en la casa, otorgando amplia libertad de acción a sus parejas.

[...] ellos son los más afortunados que yo, porque ellos hicieron su vida, ellos tuvieron sus hijos, porque la mujer siempre estaba en la casa. No en mi caso, que yo era la mujer, no podía hacer la vida que ellos hacían, porque aparte de yo ser la mujer, tenía que preocuparme de la casa, de mi hijo y de mi madre (MERY, 2012).

\section{Consideraciones finales}

Volcarse a la vida militante, a la violencia como nos dice Mery en un momento, no puede ser entendida sin tener en consideración las relaciones de género y de poder existentes dentro de la estructura partidaria. En los quiebres 
existentes en su testimonio - asociado al sentimiento de pérdida, al peso de los patrones de género que hacen dudar de las decisiones tomadas, entre otras-, es posible develar la complejidad para las mujeres militantes pertenecientes al brazo armado del PCCh de asumir responsabilidades operativas o de mayor mando, sin que ello significara tranzar y poner en juego una serie de dimensiones vinculadas con el deber del género y que los sujetos militantes, al ser hombres y poseer una mejor posición, no significaba mayor problema.

Para quienes conocieron a Mery y militaron junto a ella, ya sea en el asalto al cuartel Borgoño de la Central Nacional de Inteligencia (CNI) o en la toma de innumerables radios de la capital, en el rescate de Fernando Larenas -uno de los primeros jefes de las unidades político - militares quien fue detenido en una clínica de los aparatos represivos de la dictadura-, ella no era vista como sus esposas u otras compañeras, ella era aguerrida y nunca se negaba a ejecutar una acción.

No obstante, su representación nos da cuenta que esa libertad, ese convencimiento y convicción por la lucha armada no era producto del azar, sino más bien constituía una decisión personal y política que hizo Mery en un momento histórico de su vida donde era mejor pelear por una patria libre para su hijo, que vivir bajo opresión. Hoy esa decisión se pone en cuestión al mirar en retrospectiva, al ser negada su memoria no sólo por la oficialidad en cuanto su relato no se vincula con la de las víctimas por nunca caer en tortura, como tampoco desde la historia oficial del PCCh quien negó durante largos años la existencia del FPMR. La memoria suelta de Mery no se encuentra representada por una memoria emblemática (STERN, 2002) manteniéndose en una frágil dimensión al no ser validada por la sociedad o sus cercanos.

Por su parte, la historia política del Frente Patriótico Manuel Rodríguez, de carácter incipiente y dando sus primeros pasos, ha visibilizado el accionar de mujeres militantes y los eventuales conflictos al interior de la estructura, por su condición de mujer militante, de madre y compañera. Tan sólo investigaciones del Movimiento de Izquierda Revolucionaria (MIR) han centrado su mirada en la participación de mujeres combatientes desde una mirada del género. A su vez, en el documento del FPMR contemporáneo a la resistencia armada, visibiliza las combatientes como un sujeto importante y relevante en su organización. No obstante, aún quedan vivencias y relatos identitarios por reconocer. 
El presente artículo no tenía como objetivo reconstruir la historia del Frente Patriótico Manuel Rodríguez, sino más bien en visualizar una historia de vida de una militante, violenta y madre a la vez. De manera de aportar al reconocimiento de los sujetos mujeres, en la complejidad de sus relatos -en constante tensión en el conjunto de relaciones de género que median cualquier estructura partidaria-, en la reconstrucción de la historia de nuestro pasado presente, ya no desde la posición de la víctima, sino como combatientes que entregaron su vida a la construcción de una patria libre. 


\title{
CLANDESTINIDADE E LUTA ARMADA: UM OLHAR DE GÊNERO. O CASO DE "MERY" NA CLANDESTINIDADE DO PARTIDO COMUNISTA DO CHILE
}

\section{Resumo:}

Este artigo centraliza suas preocupações na participação das mulheres na luta contra a ditadura militar no Chile (1973 - 1988), com o objetivo de ir desvelando as relações de gênero estabelecidas dentro da militância clandestina. Para perceber isso, recorremos à memória de uma mulher militante da Frente Patriótica Manuel Rodríguez, que através do testemunho de sua experiência expõe aspectos da vida militante a partir de sua posição de mulher, mãe e clandestina, que permitem revelar o lugar ocupado pelas mulheres no braço armado do Partido Comunista do Chile.

Palavras-chave: Gênero. Militância. Identidade.

\section{CLANDESTINENESS AND ARMED STRUGGLE: A GENDER PERSPECTIVE. THE CASE OF "MERY" IN THE CLANDESTINENESS OF THE COMMUNIST PARTY OF CHILE}

\begin{abstract}
:
This paper focuses its concern on the participation of women in the struggle against the military dictatorship in Chile (1973 - 1988), with the aim of revealing the gender relations established within the clandestine militancy. To realize this, we turn to memoria suelta of a woman activist from Frente Patriótico Manuel Rodríguez, who, through the testimony of her experience, exposes militant aspects of life from her position as woman, mother and clandestine, unveiling the place occupied by women in the armed wing of the Communist Party of Chile.
\end{abstract}

Keywords: Gender. Militancy. Identity. 


\section{Referencias}

BASABE, Omar; SADI, Marisa. La significación omitida. Militancia y lucha armada en la Argentina reciente". Buenos Aires: Catálogos, 2008.

COLÁS, Pilar. Género, interculturalidad e identidad: Teoría y práctica educativa. In: Género e interculturalidad: educar para la igualdad. Madrid: La Muralla, 2006.

GROPPO, Bruno. Las políticas de la memoria. Revista Sociohistórica. Cuadernos del CISH. Volumen 11/12. Facultad de Humanidades y Ciencias de la Educación. Universidad Nacional de La Plata. Buenos Aires, 2002.

LARRAÍN, Jorge. Identidad chilena. Santiago: LOM, 2001.

FRENTE PATRIÓTICO MANUEL RODRÍGUEZ. Manuel Cabalga de Nuevo. Santiago: Frente Patriótico Manuel Rodríguez. 1986.

MERY. Entrevista realizada por Javiera Robles Recabarren. Santiago, Chile, 17 mar. 2012. Transcrito por Javiera Robles Recabarren.

MOYANO, Cristina. MAPU o la seducción de poder y la juventud. Los años fundaciones del partido - mito de nuestra transición (1969 - 1973). Santiago: Ediciones Universidad Alberto Hurtado, 2009.

ROJAS, Luis. De la rebelión popular a la sublevación imaginada. Antecedentes de la Historia Política y Militar del Partido Comunista de Chile y del FPMR 1973 1990. Santiago: LOM, 2011.

KOTCHERGENKO, Andrei Martin San Pablo. As mulheres na luta armada no Cono Sul. In: Resistências, Gênero e Feminismos contra as ditaduras no Cono Sul. Florianópolis: Editora Mulheres, 2011.

STERN, Steve. De la memoria suelte a la memoria emblemática: Hacia recordar y el olvidar como proceso histórico (Chile, 1973 - 1998). In: Las conmemoraciones: las disputas en las fechas 'in-felices'. Madrid: Siglo XXI, 2002.

Dossiê:

Recebido em: Março/2013

Aceito em: Maio/2013 